\title{
The Cabinet de mathématiques of the Henri Poincaré Institute in Paris
}

The article is a historical overview of the rich collection of mathematical models stored at the Henri Poincaré Institute in Paris. The text focuses on the three main sources from the end of the nineteenth century and presents some new additions related to today's mathematics.

Keywords: mathematical models, $19^{\text {th }}$-century mathematics, $20^{\text {th }}$-century mathematics, Gaston Darboux, Joseph Caron, Théodore Olivier, the Muret collection, the Schilling collection, campylograph

Słowa kluczowe: modele matematyczne, matematyka XIX w., matematyka XX w., Gaston Darboux, Joseph Caron, Théodore Olivier, kolecja Mureta, kolecja Schillinga, kampylograf

\section{The Cabinet}

Natural sciences such as botany, zoology, mineralogy, and crystallography, to name just a few, classify the objects of their studies in series and often display those objects in showcases that prevent direct contact with the general public. Such a showcase is called a Cabinet. ${ }^{1}$

Similarly, and contrary to popular belief, the mathematics used to do the same. Such a cabinet de mathématiques existed at the Sorbonne during the second half of the nineteenth century (Fig. 2) and was directed by Gaston Darboux (1842-1917) (Fig. 1). However, between 1930 and 1980, i.e. in the period of systematic algebrisation of mathe-

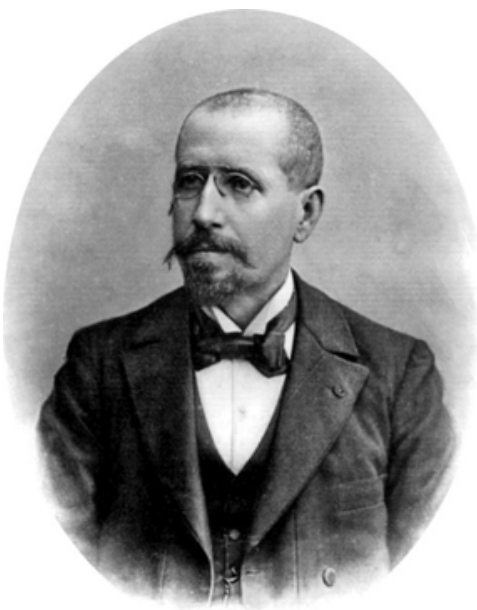

Figure 1. Gaston Darboux (Source: doctoral thesis, Barnabé Croizat, 2016). 


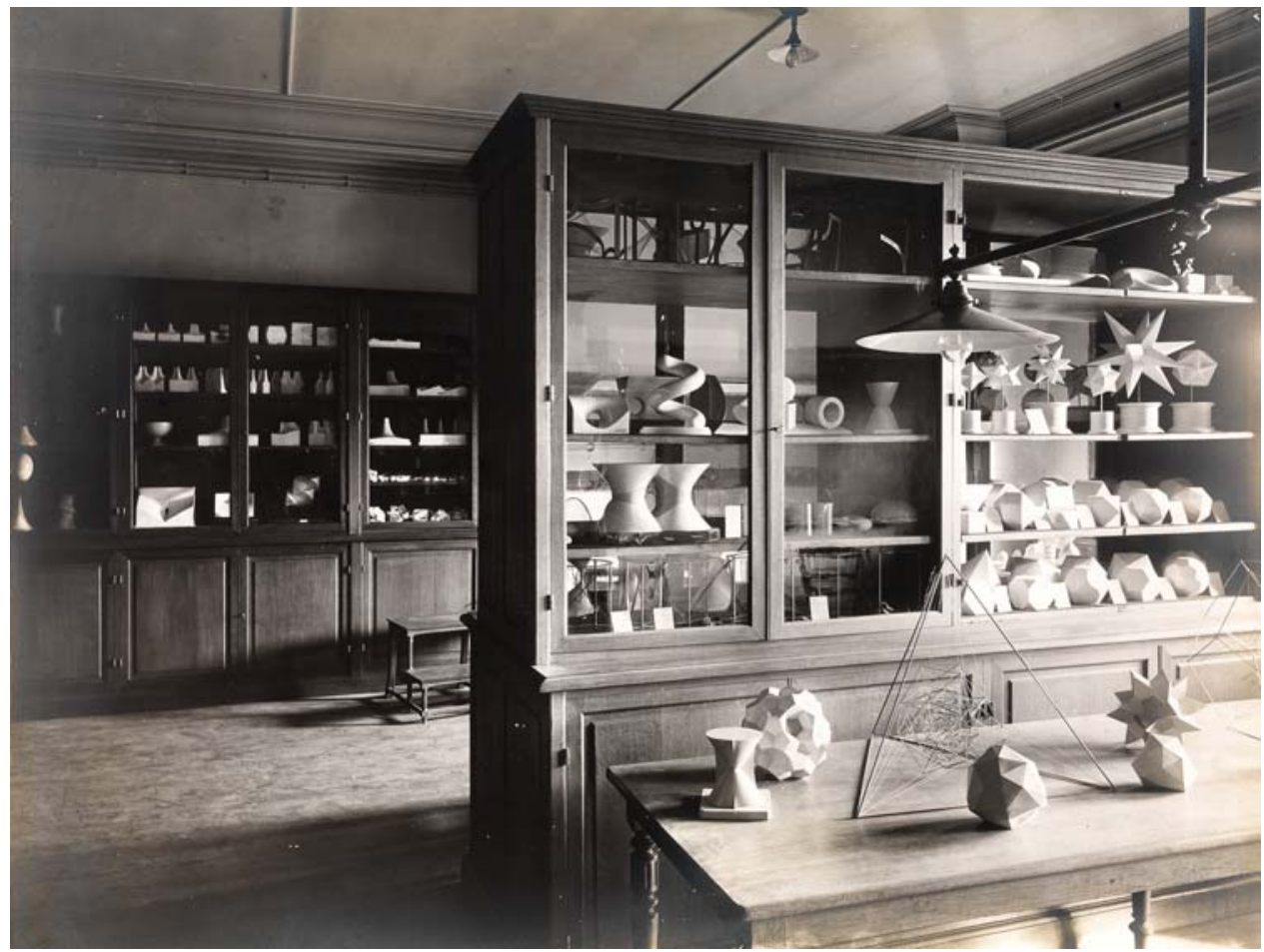

Figure 2. The Cabinet de mathématiques at the Sorbonne before 1914 (Source: Ch. Barenne, IHP).

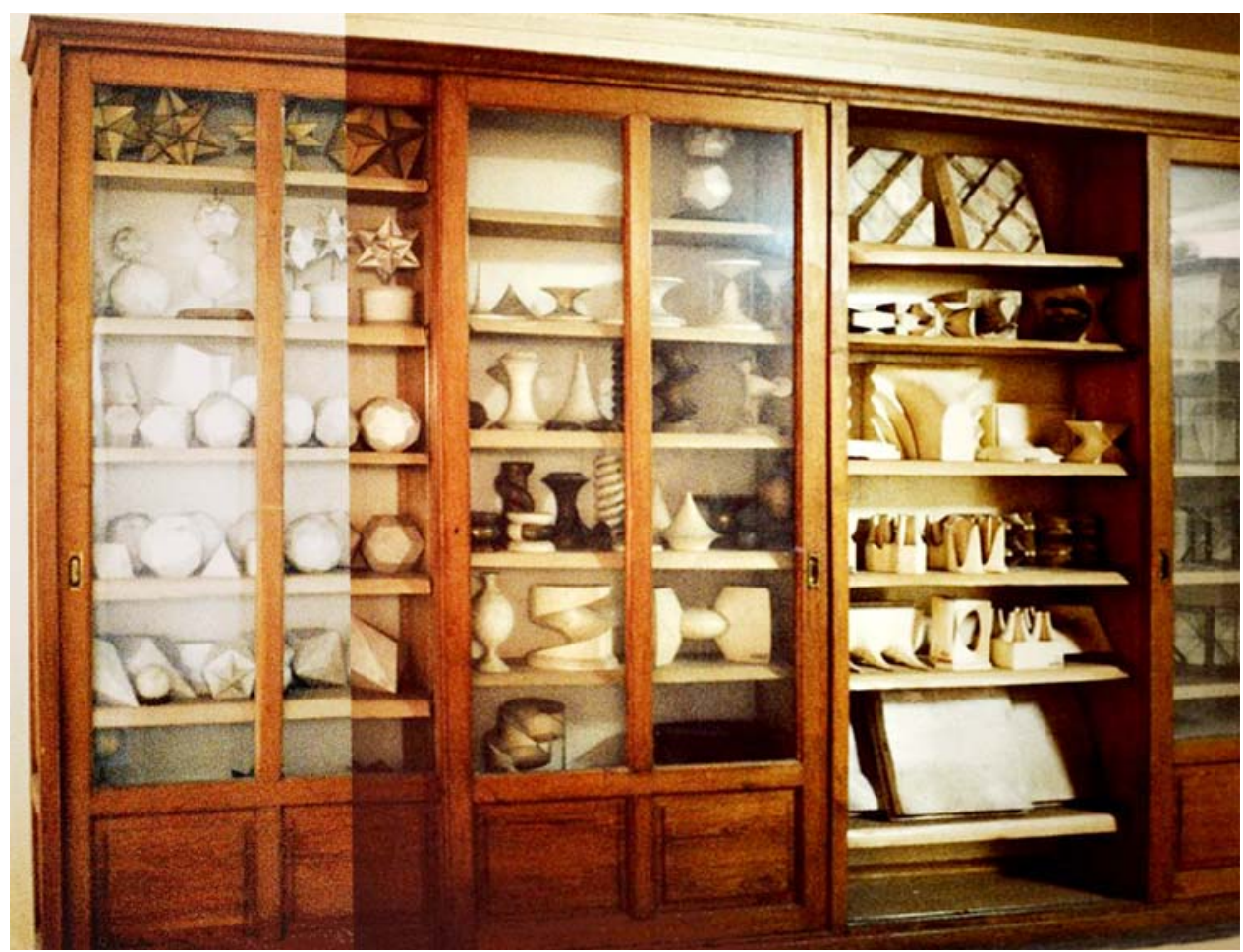

Figure 3. The Cabinet, after 1945, photographic montage (Source: IHP). 
matics in France, people lost interest in such collections, which, in turn, meant that they were often damaged, dispersed, or that they completely disappeared.

Since 2009, under the direction of Cédric Villani, the Henri Poincaré Institute (Institut Henri Poincaré, IHP), which inherited the Sorbonne collection in 1928 (Fig. 3), has decided to give it a new lease on life. The IHP is gradually restoring damaged models and, thanks to 3D printing technology, is steadily adding new items illustrating today's mathematics. Here, I wish to present this collection of over 600 pieces in its historical and scientific contexts.

\section{The main sources}

It seems that the principal idea behind the formation of the collection which is currently housed in the IHP was partly triggered by the desire to present a complete series of objects in the same spirit as zoologists do - for example: Platonic polyhedra, Archimedean polyhedra, Catalan polyhedra, cyclides, quadrics, cubic surfaces, etc.

However, when we consider even the very first models (created from the year 1830 by Théodore Olivier (1793-1853), Fig. 4), it appears that the idea of a complete series was not the ultimate goal.

The aim was rather to physically illustrate descriptive geometry exercises, a field that Olivier learned from Gaspard Monge at the École Polytechnique (Paris) and that he taught at the École Centrale des Arts et Manufactures (Paris). If approximately

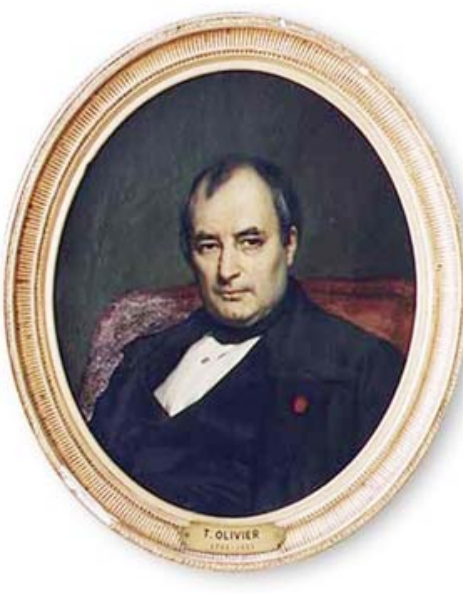

Figure 4. Théodore Olivier (Source: Wikipedia). fifty models produced by Olivier are essentially quadrics and their intersections, then they should be treated as a response to the curriculum rather than the desire to exhaust a list.

Only four of Olivier's models, currently in poor condition, are held at the IHP and are mentioned here because they are the oldest in the collection.

Olivier's contribution, in comparison to earlier silk string models, is deformability. One can modify the given geometric shape by an appropriate system of linkages and flyweights, transforming, for instance, a cylinder into a one-sheeted hyperboloid while keeping the string threads tensioned (Fig. 5).

In 1875, Charles Muret (1852-1910) published a catalogue of 600 models, $^{2}$ mostly cast in plaster and used for teaching in schools of fine arts or architecture, as well as for helping students in educational institutions at all levels in order to grasp the subtleties of space geometry through touch and sight. About 400 of them have a direct bearing on mathematics. Although initially they were all acquired by the Sorbonne Cabinet de mathématiques, several of them were lost or destroyed. Nevertheless, the IHP collection still 


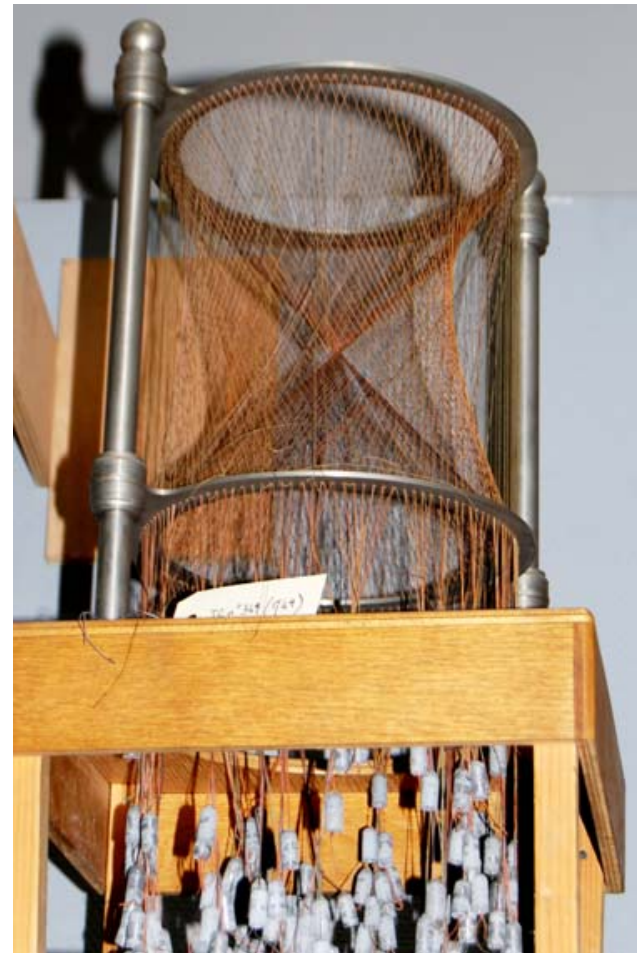

Figure 5. One-sheeted hyperboloid and its asymptote cone, Th. Olivier (Source: the IHP collection).

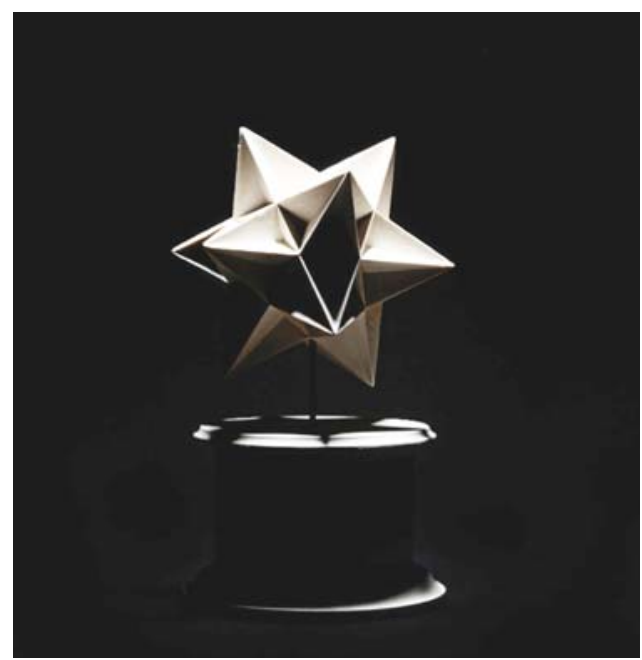

Figure 6. Great icosahedron, Ch. Muret (Source: the IHP collection). holds more than 150 of them, including a complete series of polyhedra (Fig. 6), quadrics, cyclides (Fig. 7), and conoids.

1870 marks the beginning of the golden era for modelling and the production of mathematical objects intended to illustrate Brill and Klein's exercises taught at the Mathematical Institute of the Technische Hochschule in Munich. As a result, Ludwig Brill started a company in 1880, and Walther Dyck created a mathematical museum in 1893.

Brill's company was taken over by Martin Schilling in 1899. The catalog of this new company described 40 series of models consisting of more than 450 items. ${ }^{3}$ The Sorbonne Cabinet de mathématiques purchased the main part of Schilling's collection before World War I, and all that remains of it today still accounts for a third of the IHP collection (Figs. $8,9,10$, and 11).

The third and largest component of the IHP collection is unique in the world. Unlike the collections of Olivier, Muret, and Schilling, which were sold to leading mathematical institutes at the end of the nineteenth century, this collection consists of models produced by Joseph Caron) 1849-1924) (Fig. 12) between 1900 and 1915.

In 1871, Caron was appointed as professor of descriptive geometry at the $L y$ cée Saint-Louis in Paris, and as director of graphical works at École Normale Supérieure (Paris) a year later. His acute sense of geometric reality, combined with an interest in practical realisations, influenced young Henri Lebesgue and turned Lebesgue's attention toward geometrical constructions. In 1872, Gaston Darboux was appointed to the École Normale Su- 
périeure, when Caron was in charge of the graphical works. Caron supervised students in solving the exercises of descriptive geometry taken from Darboux's lectures. Caron, a skilled cabinetmaker, began producing a systematic series of mathematical models in order to illustrate the solutions to Darboux's geometric problems (Figs. 13, 14, 15, 16 , and 17). In 1915, World War I halted the production process.

Caron produced more than 150 objects, mostly in wood, but some in cardboard and wire as well. ${ }^{4}$

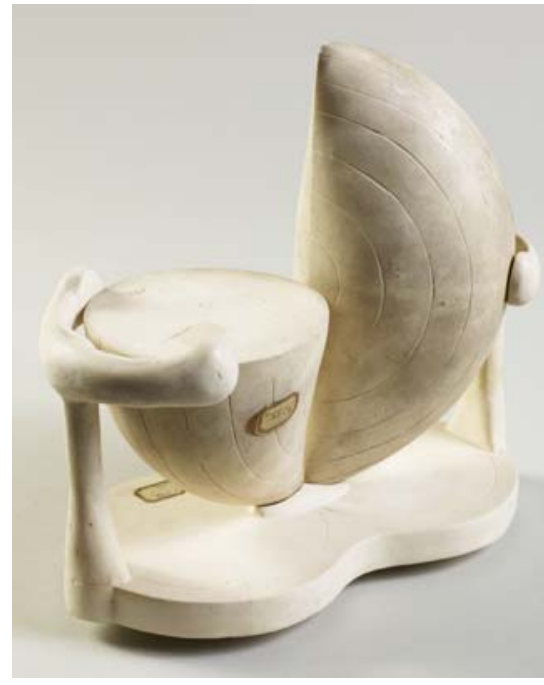

Figure 7. Spindle cyclide, Ch. Muret (Source: the IHP collection).

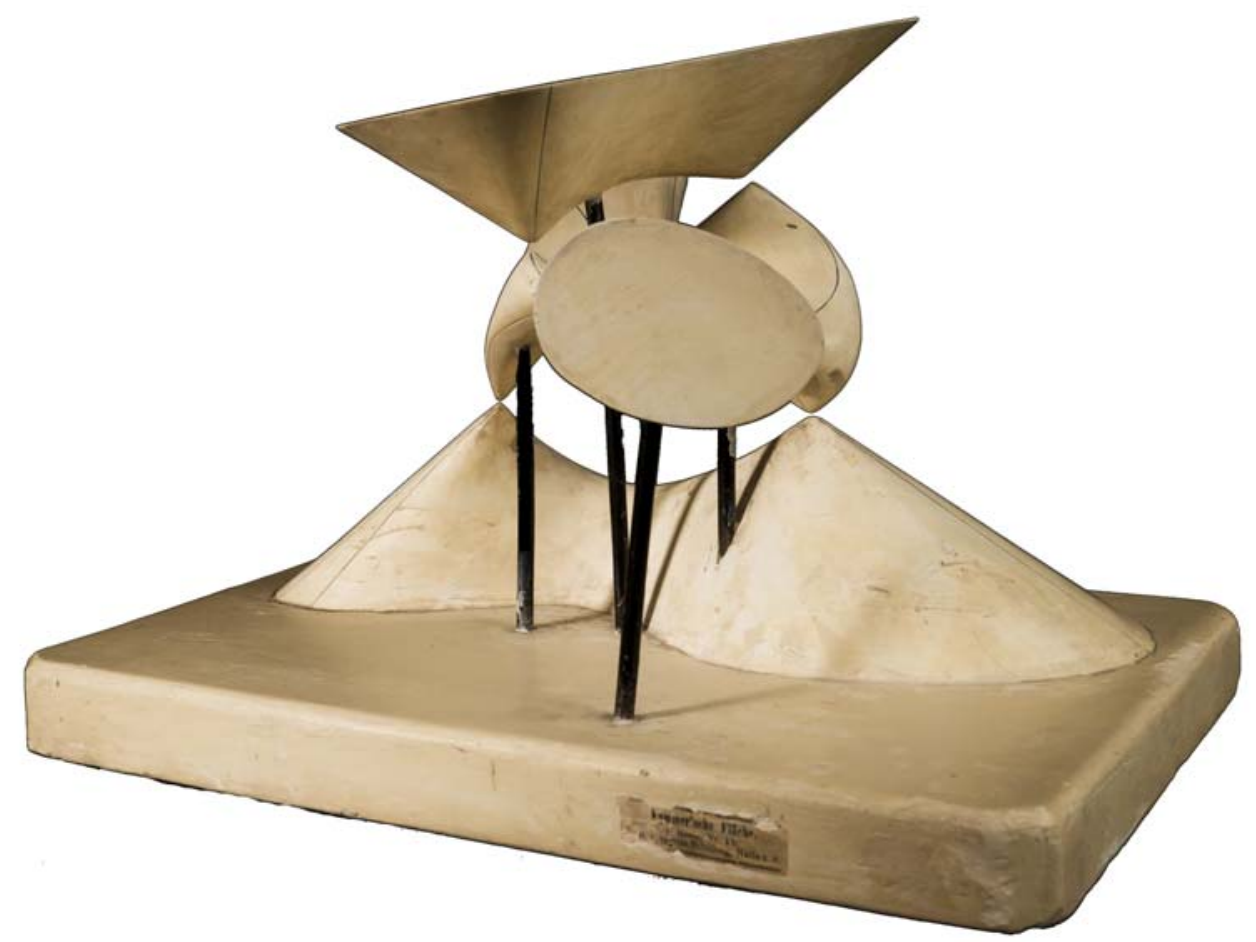

Figure 8. Kummer surface with 8 double points, Schilling's catalogue (Source: the IHP collection). 


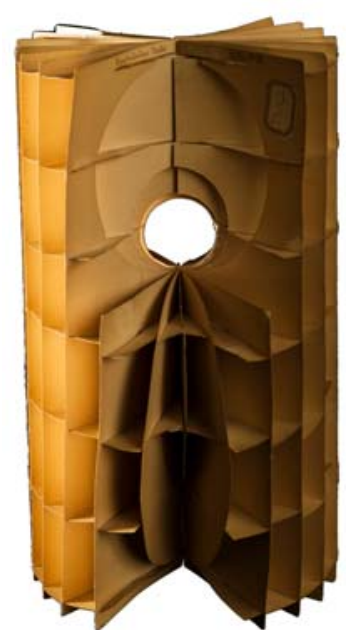

Figure 9. Negative curvature, Schilling's catalogue (Source: the IHP collection).

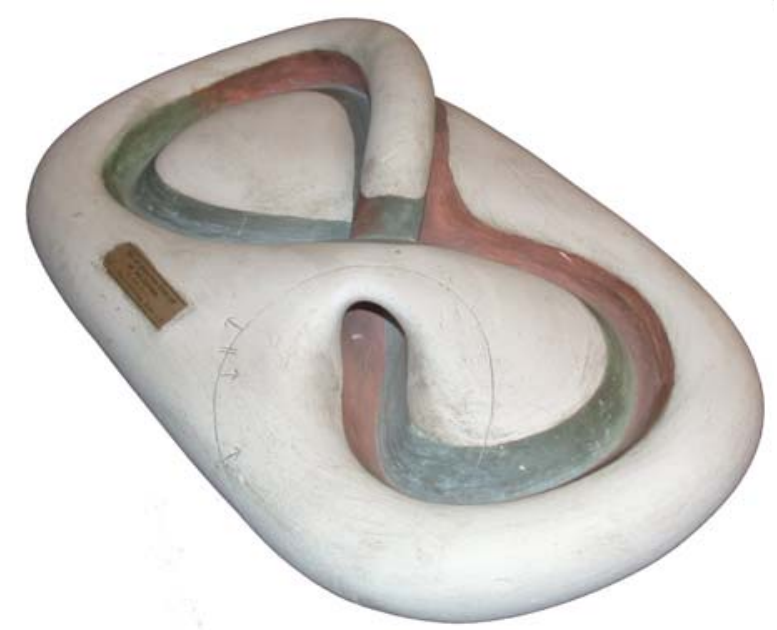

Figure 10. Boy's surface, the first version, Schilling's catalogue (Source: the IHP collection).

\section{Further sources}

The IHP collection also includes some scientific instruments of which the campylograph is the most spectacular one..$^{5}$

The campylograph is a mechanical curve plotter (Fig. 18). It was created by a Swiss Jesuit, Father Marc Dechevrens (1845-1923) (Fig. 19), director of the Jersey Observatory (English Channel). His machine was designed to trace out epicycles in order to model, according to the old Ptolemaic system, the apparent path of the planets viewed in the ecliptic plane with the Earth as a fixed point. He revealed his invention during two sessions of the Académie des Sciences in Paris on 11 June and 13 August 1900.

The machine was exhibited at the Palais de la Découverte during the Universal Exhibition in Paris in 1937. It can plot a variety of curves, including circles, ellipses, parabolas, Lissajous curves, Tchebycheff curves, epicycloids, epitrochoids, braids, and more general ornamental curves.

The above overview of the IHP Cabinet de mathématique might suggest that mathematics has remained frozen since the end of the nineteenth century. This impression is false. The major collections ended due to the outbreak of World War I on the one hand, and to the algebrisation of mathematics during the 1930s on the other, which made the use of concrete objects obsolete. Furthermore, it is worth recalling a massive tidal wave triggered by the 'modern math' at the end of the 1960s, both in school and university curricula in France, in order to better understand the rejection of using drawings and a fortiori of physical models.

However, over many decades, people have continued to produce mathematical models of which several have been incorporated to the IHP collection (Figs. 20, 21, 22, and 23). 


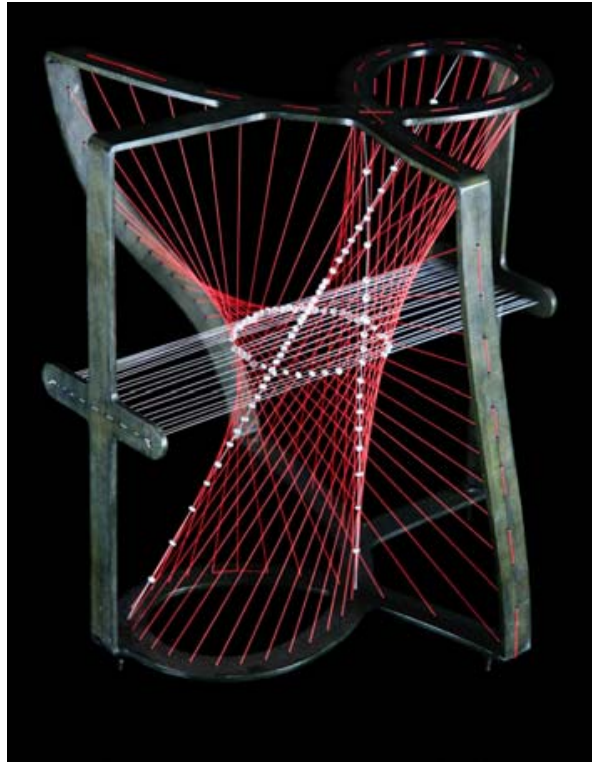

Figure 11. Ruled cubic, Schilling's catalogue (Source: the IHP collection).

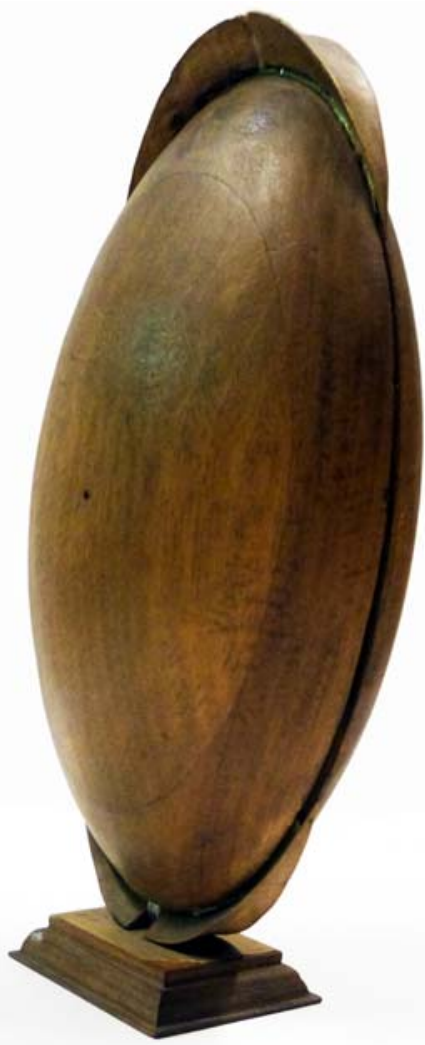

Figure 13. Wave front, Joseph Caron, 1914 (Source: the IHP collection).

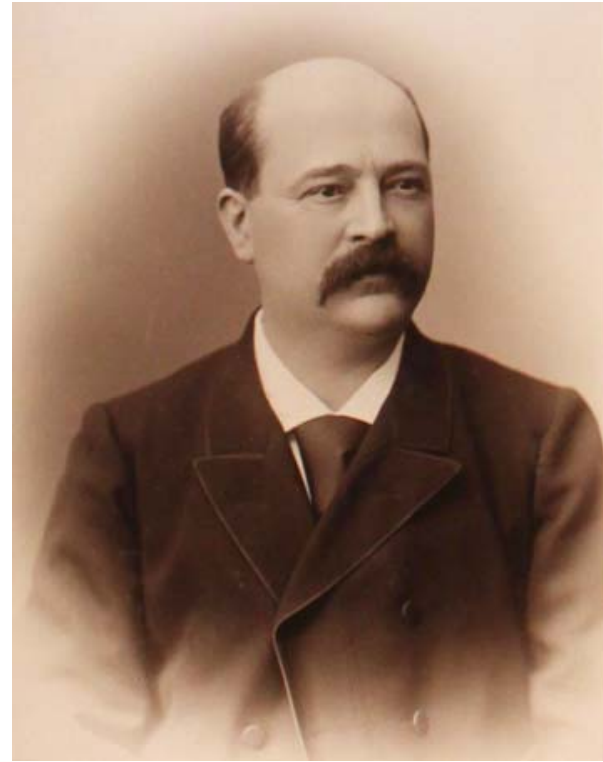

Figure 12. Joseph Caron (Source: Album du centenaire, A. Gerschel \& fils, E.N.S., bibliothèque des lettres et sciences humaines, fonds photographique).

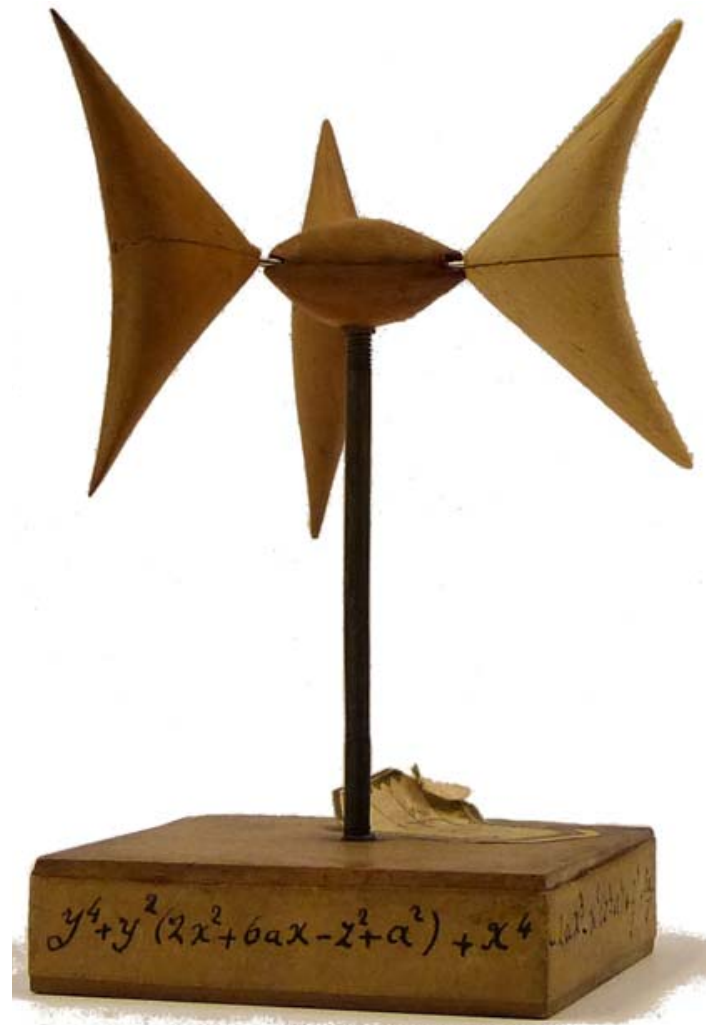

Figure 14. Quartic, Joseph Caron, ca. 1910 (Source: the IHP collection). 


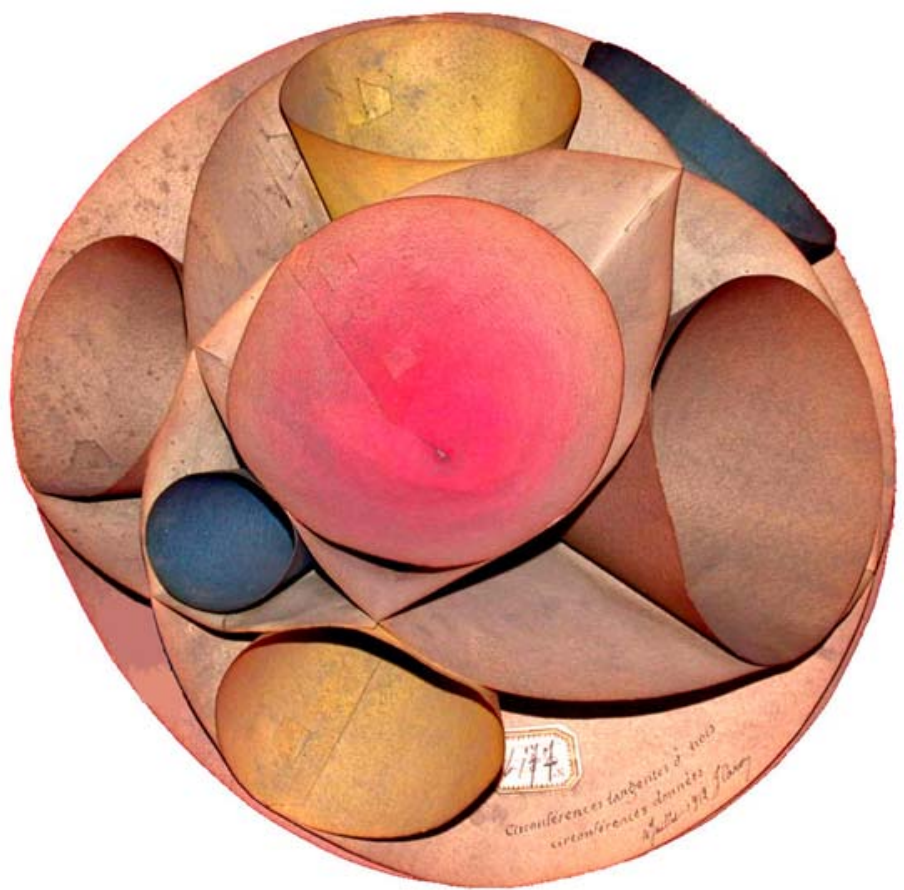

Figure 15. Eight circles tangent to three circles on the sphere, Joseph Caron, 1912 (Source: the IHP collection).

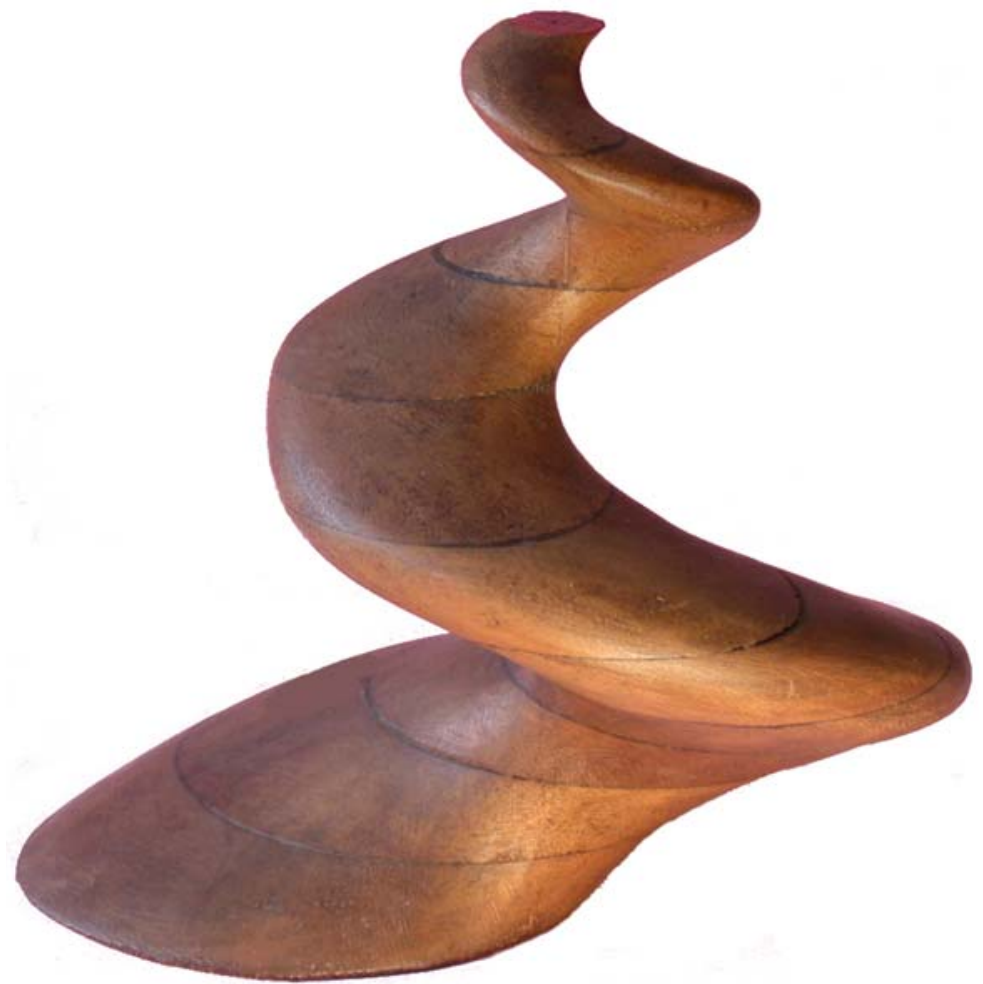

Figure 16. Canal surface, Joseph Caron, ca. 1910 (Source: the IHP collection). 


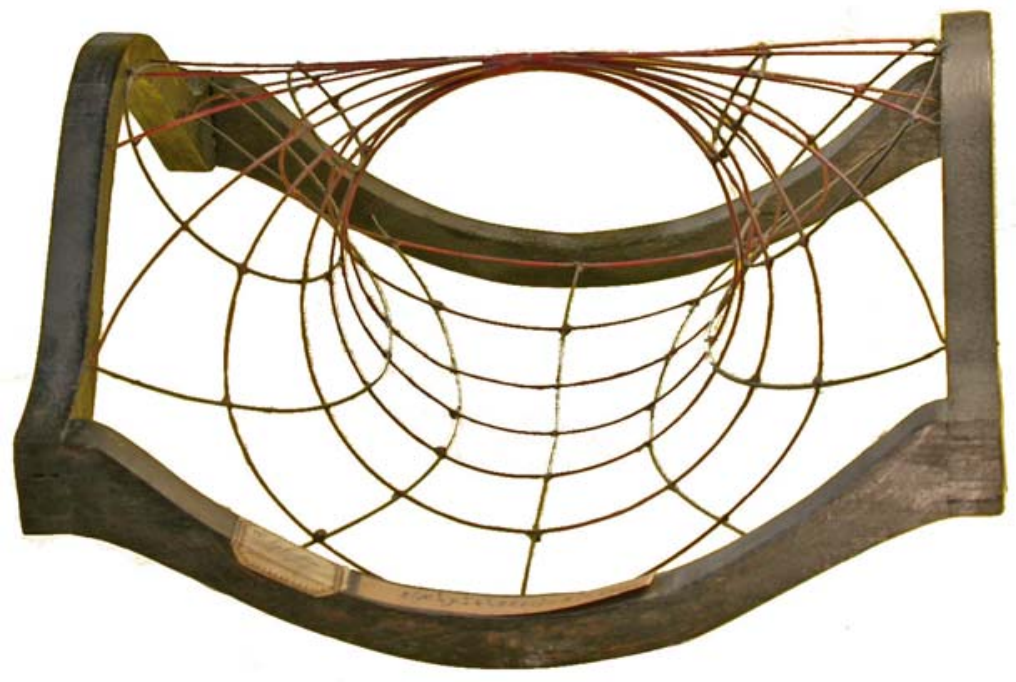

Figure 17. Parabolic cyclide, Joseph Caron, ca. 1912 (Source: the IHP collection).

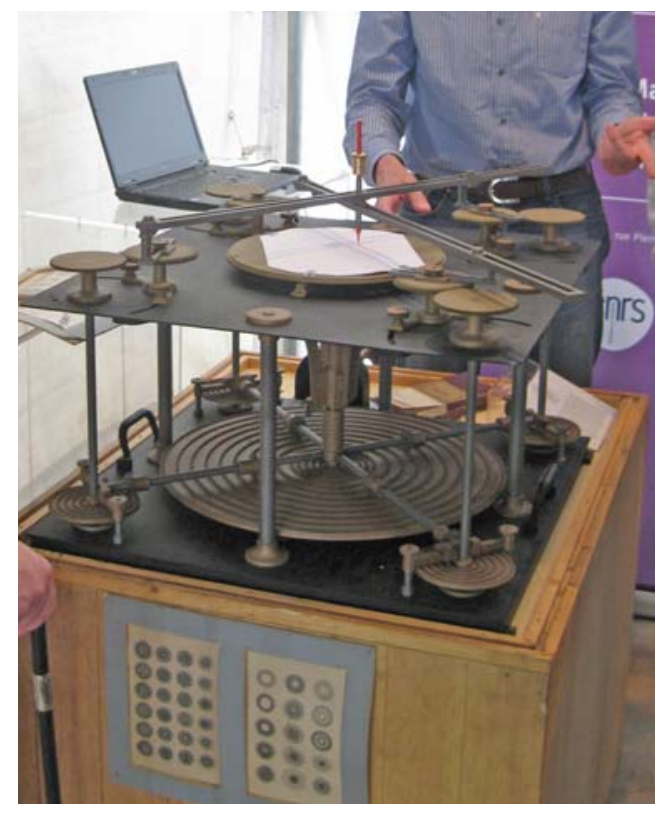

Figure 18. The campylograph (Source: the IHP collection).

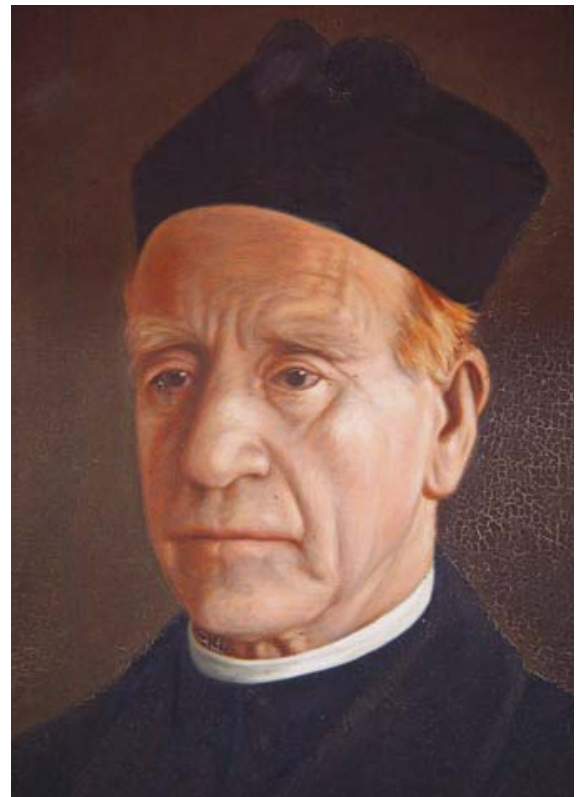

Figure 19. Father Marc Dechevrens (Source: Maison St. Louis Observatory, Jersey, United Kingdom).

Nowadays, 3D-printing technology not only enables the reproduction of old, damaged, or lost models at a reasonable cost, but also enriches the collection with new elements based on contemporary mathematical problems (Figs. 24, 25, and 26). 

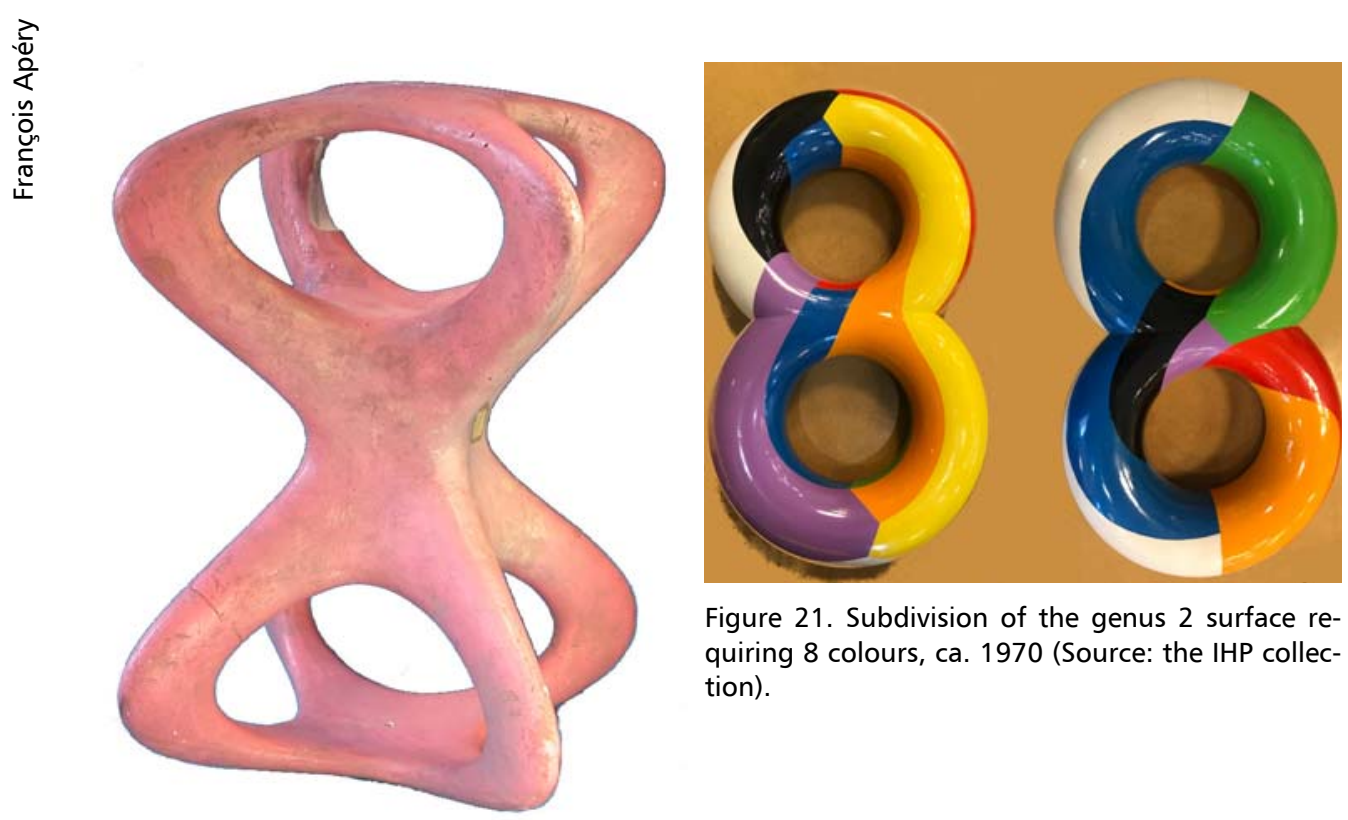

Figure 21. Subdivision of the genus 2 surface requiring 8 colours, ca. 1970 (Source: the IHP collection).

Figure 20. Surface of genus 6, Maurice El-Milick, 1947 (Source: the IHP collection).

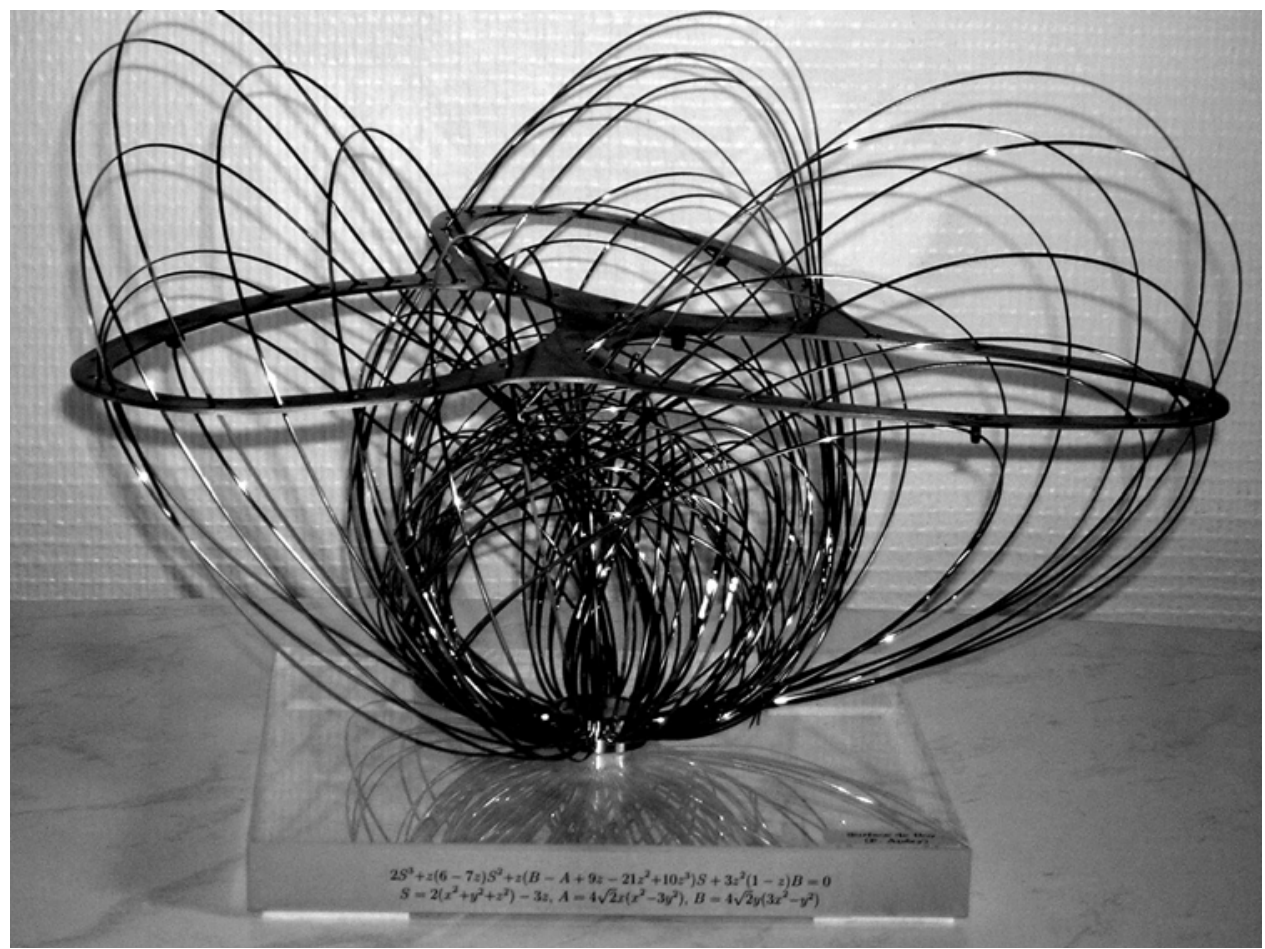

Figure 22. Algebraic Boy's surface of degree six, F.A., 1992 (Source: the IHP collection). 

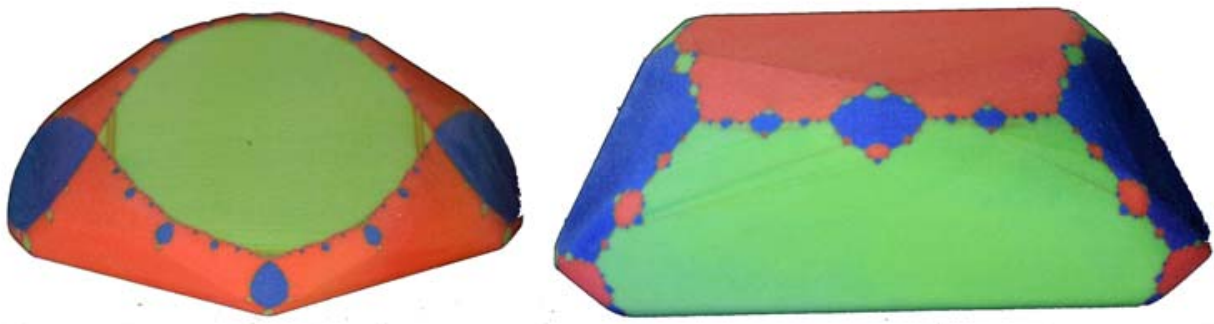

Figure 24. Julia-McMullen convex of $z^{2}-1$ (left) and $1-z^{-2}$ (right), Laurent Bartholdi, 2014 (Source: the IHP collection).

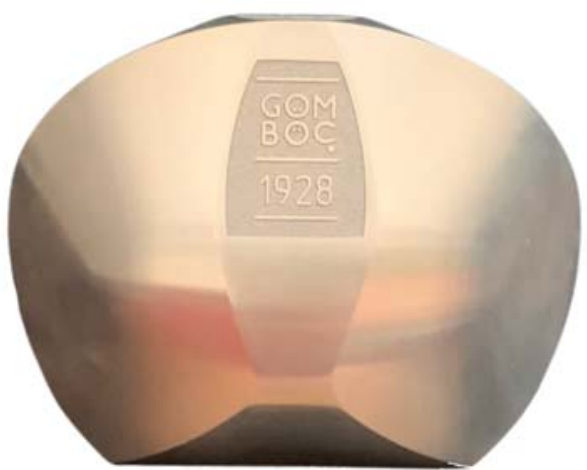

Figure 23. Gőmbőc, Gábor Domokos \& Péter Várkony, 2006 (Source: the IHP collection).

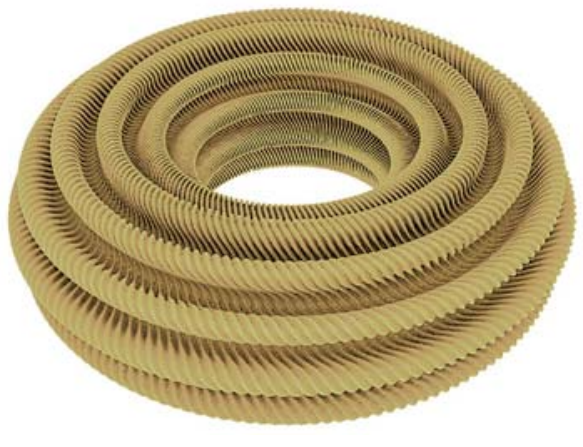

Figure 26. Flat torus, 2017 (Source: the IHP collection).

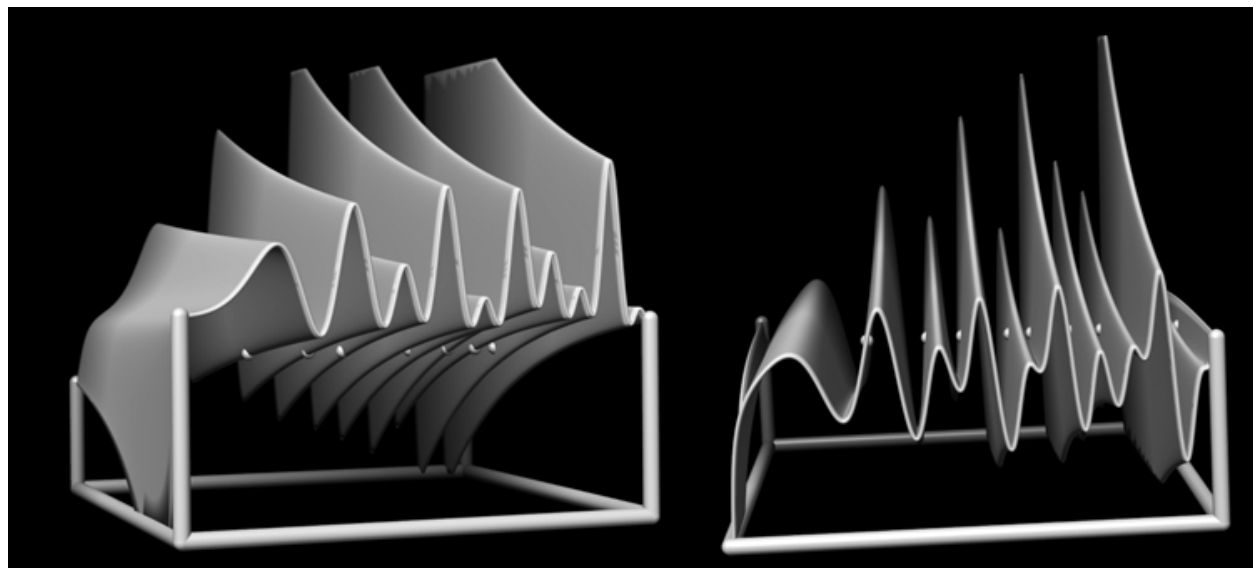

Figure 25. Real and imaginary parts of the Riemann zeta function in the neighbourhood of the first ten zeros, 2017 (Source: the IHP collection). 


\section{Bibliography}

Apéry F., Caron's Wooden Mathematical Objects, [in:] Mathematics and Art III, ed. by C.P. Bruter, Paris 2015, p. 39-48.

Apéry F., Constructing Wire Models, [in:] Mathematics and Arts, ed. C. Bruter, Berlin, Heidelberg 2002, p. 179-200, DOI 10.1007/978-3-662-04909-9_21.

Apéry F., Le campylographe, "Quadrature" no. 100, 2016, p. 24-32.

Apéry F., Old and New Mathematical Models: Saving the Heritage of the Institut Henri Poincaré, [in:] Mathematics and Modern Art. Proceedings of the First ESMA Conference in Paris, ed. by C. Bruter, Berlin, Heidelberg 2012, p. 17-28, DOI 10.1007/978-3-64224497-1_3.

Apéry F., The Art of the Model, [in:] The House of Mathematics, ed. by C. Villani, J.-P. Uzan and V. Moncorgé, Paris 2014, p. 130-131.

Apéry F., The Models Chosen by Man Ray at the Institut Henri Poincaré: A Mathematician's View, [in:] Man Ray. Human Equations, ed. by W.A. Grossman and E. Sebline, Ostfildern 2015, p. 106-109.

Muret C., Choix de modèles en plâtre et en fil, Paris ca. 1875.

Objets mathématiques, preface by C. Villani and J.-P. Uzan, Paris 2017.

Schilling M., Catalog mathematischer Modelle, Leipzig 1911.

Professor François Apéry graduated from École Normale Supérieure de Cachan (class of 1971). He received his PhD in 1984 in Strasbourg under the supervision of Bernard Morin. He defended his DSc thesis on differential topology in 1994. He is associate professor emeritus at the University of Upper-Alsace in Mulhouse and the scientific referee of the Henri Poincaré Institute collection of mathematical models in Paris.

E-mail: francois.apery@uha.fr

Article submitted on 6 December 2019

Article accepted on 13 March 2020

\section{Cabinet de mathématiques w Institut Henri Poincaré w Paryżu}

Artykuł przedstawia historyczny przegląd bogatej kolekcji modeli matematycznych Institut Henri Poincaré w Paryżu. Tekst skupia się na trzech głównych źródłach z końca XIX w., oraz przedstawia kilka nowych elementów związanych ze współczesną matematyką. 